\title{
Age at diagnosis and abilities in idiopathic hypercalcaemia
}

\author{
O UDWIN, W YULE, AND N D T MARTIN
}

Department of Psychology, Institute of Psychiatry, and Department of Paediatric Cardiology, Guy's Hospital, London

SUMMARY Forty three children aged 6 to 16 years with a documented history of idiopathic infantile hypercalcaemia were assessed on a variety of cognitive and behavioural measures. No relation was found between the age at which hypercalcaemia was diagnosed and subsequent full scale intelligence quotients (IQ) and reading or spelling abilities. Verbal IQ was, however, significantly higher than performance IQ, which had an inverse relation with age at diagnosis. Furthermore, scores for deviant behaviour were found to correlate with age at diagnosis. Thus the characteristic psychological profile of this syndrome may be in part a function of hypercalcaemia during infancy.

Idiopathic infantile hypercalcaemia was first recognised in 1952 by Fanconi et al, Lightwood, and Payne. ${ }^{1-3}$ Most authors have distinguished 'mild' cases of idiopathic infantile hypercalcaemia, ${ }^{4}$ who make a complete recovery, from 'severe' cases, ${ }^{1}$ who present in a similar fashion but are characterised by congenital defects and considerable long term morbidity. It is as yet unproven whether the two forms represent differing polarities of the same pathological process or two separate disease entities. ${ }^{5}$ The focus in this study is on the severe form of idiopathic infantile hypercalcaemia of the Fanconi type.

Features of the syndrome include a distinctive 'elfin like' facies, ${ }^{6}$ renal and cardiovascular abnormalities (supravalvular aortic stenosis and peripheral pulmonary artery stenosis), ${ }^{57}$ and moderate to severe degrees of mental handicap. ${ }^{8-10}$ The children also have a peculiar psychological profile and specific personality characteristics, which seem to distinguish them from other mentally handicapped groups. Their verbal abilities tend to be superior to their visuospatial and motor skills, ${ }^{9}{ }^{11}$ and they show high rates of emotional and behavioural disturbances and hyperactivity. ${ }^{811}$

The cause of the syndrome is unknown. Prenatal growth is involved as the birth weights of the affected children are significantly lower than normal, and cardiac murmurs are often noted at birth. ${ }^{7}$ Symptoms of hypercalcaemia present during the first year, the peak being between 5 and 8 months of age; ${ }^{12}$ but there is often considerable delay between. the onset of symptoms and diagnosis. Martin et af found the mean age at diagnosis to be 12 months, ${ }^{\text {T }}$ and the mean time from the stated onset of problems to diagnosis was nine months. The cause of hypercalcaemia may be increased intestinal absorption of calcium. As evidence of excessive vitamin $\mathrm{D}$ intake during infancy has not been found, ${ }^{7}$ other theories have been proposed, including vitamin $\mathrm{D}$ 'sensitivity'. ${ }^{13}$ Martin et al found normal concentrations of vitamin D metabolites in plasma, however, in both the hypercalcaemic and normocalcaemic phases of the syndrome. ${ }^{14}$

It has been suggested that hypercalcaemia per se may account for the mental handicap seen in the Fanconi type of idiopathic infantile hypercalcaemia and that delay in diagnosis may have a deleterious effect on cognitive development. ${ }^{5} 12$ This important question has not previously been studied. In 31 cases where cognitive or developmental assessment results were available a significant negative correlation between age at diagnosis and subsequent intelligence and developmental quotients has been found. (Martin NDT. Personal communication.) These data were, however, retrospective, obtained from hospital records, and based on a range of different tests administered by different testers. Most children were assessed in infancy on the Griffiths scales, but others were assessed when they were of school 
age on the Wechsler intelligence scale for children or the Stanford-Binet intelligence test. Clearly, different skills and abilities had been assessed at different stages of development on different tests.

The present study examines the relation between age at diagnosis and subsequent cognitive abilities, attainment, and behaviour in 43 mentally handicapped, school aged children with documented evidence of hypercalcaemia in infancy who had been treated with low calcium and vitamin D restricted diets.

\section{Subjects and methods}

The children were drawn from the membership of the Infantile Hypercalcaemia Foundation, a parent support group that holds the only register of affected children in the United Kingdom. The parents of 52 children (who had an age range of 6-16 years) known to the Foundation were approached for permission to include their children in the study. Consent was obtained for 49 of the children. Thirty three of these children had been examined by Martin et al as part of an earlier study and had been found to fulfil the criteria suggested by these authors for a diagnosis of the Fanconi type idiopathic infantile hypercalcaemia. ${ }^{7}$ The hospital records of the remaining 16 children were examined and evidence for a diagnosis of the Fanconi type of idiopathic infantile hypercalcaemia in accordance with these criteria was found in 10 cases. The final sample thus comprised 43 children. Characteristics of the sample and medical data obtained from hospital records are presented in the Table. All the children had been placed on a low calcium and vitamin $\mathrm{D}$ restricted diet after diagnosis, for periods ranging from six to 66 months, and a few were still on the diets at the time of the present study.

Each child was seen individually, either at school (34 children) or at home (nine), and assessed on the following measures, without specific knowledge of the age at which the diagnosis had been made:

(1) Intelligence was determined using the Wechsler intelligence scale for children-revised (WISC-R). ${ }^{15}$

(2) Reading and spelling attainment were assessed

Table Characteristics of the sample studied

\begin{tabular}{|c|c|c|c|}
\hline & Mean & & $(S D)$ \\
\hline Age (months) & 134.5 & & $(36 \cdot 1)$ \\
\hline Age at diagnosis (months) & 11.5 & & $(7 \cdot 8)$ \\
\hline Birth weight $(\mathrm{kg})$ & 2.7 & & $(0.5)$ \\
\hline Plasma calcium at diagnosis $(\mathrm{mmol} / \mathrm{l})$ & $3 \cdot 3$ & & $(0 \cdot 4)$ \\
\hline Sex (boys:girls) & & $20: 23$ & \\
\hline
\end{tabular}

using the Neale analysis of reading ability ${ }^{16}$ and the Vernon graded word spelling test. ${ }^{17}$

(3) Emotional and behavioural disturbance was determined by the Rutter questionnaires. ${ }^{18} 19$ In addition to the total scores on these questionnaires, subscale scores were obtained on symptom clusters of 'neurotic', 'anti-social', and hyperactive behaviours.

Statistical analysis. The Student's $t$ test for paired samples was used to compare the subjects' verbal and performance intelligence quotients (IQs), and $\chi^{2}$ tests were used to compare rates of behavioural disturbance in the present sample with those reported by other researchers for groups of normal and mentally handicapped children. The relation between age at diagnosis and measures of cognitive functioning and behaviour was examined using Pearson product moment correlations.

\section{Results}

Cognitive functioning and behaviour. For nine children $(21 \%)$ full scale IQs on the WISC-R fell below the basal level of 40 . The IQs of the remaining 34 children ranged from 40 to 89 , with a mean of $54 \cdot 6$. Overall, $54 \%$ of the sample fell into the 'severe' range of mental handicap. Only one child had a full scale IQ in the 'borderline' range, and one child came within the 'normal' range. Considering verbal and non-verbal performance IQs separately, eight children $(19 \%)$ failed to score above the floor of the verbal scale, and for the rest verbal IQs ranged from 45 to 109 , with a mean of $62 \cdot 4$. On the performance scale, 14 children $(33 \%)$ scored below the floor of the test, and the remaining children obtained a mean IQ of 55.9 (range 45-73). There was a significant difference between the scores on these two scales $(p<0 \cdot 001)$, with the verbal scale IQ being superior to the performance scale IQ.

Over half of the subjects attained some score on the Neale analysis of reading ability ( 22 children) and on the Vernon spelling test (23). The readers had a mean chronological age of 12.0 years (range $72-189$ months) and they obtained a mean age of $7 \cdot 8$ years for both reading accuracy (range 74-137 months) and reading comprehension (range 75-144 months). The spellers had a mean chronological age of $12 \cdot 1$ years (range 89-189 months) and obtained a mean spelling age of 6.8 years (range 67-136 months).

Parent and teacher ratings on the Rutter scales indicated high rates of behavioural and emotional disturbance in the sample. Altogether $53 \%$ of the children showed disturbed behaviour both at home and at school, and a further $35 \%$ were rated as 
disturbed either at home or school. Only $12 \%$ of the sample scored below the cut off for deviant behaviour on both the parent and teacher scales. These rates of disorder are significantly higher than the rates reported by Rutter et al for groups of normal children $(\mathrm{p}<0.001)$ and also mentally handicapped children $(p<0 \cdot 05) .{ }^{19}$ The children were also found to be significantly more hyperactive on these scales than both normal children $(p<0.001)$ and other mentally handicapped children $(p<0.05),{ }^{20}$ with $72 \%$ of the sample displaying hyperactive behaviour either at home or at school or in both settings.

Age at diagnosis and subsequent IQ and behaviour. In view of floor effects on the WISC-R verbal and performance IQs, the relation between cognitive abilities and age at diagnosis was examined using the sums of scaled scores on the WISC-R subtests.

Over the total sample there were no significant correlations between age at diagnosis and the sums of scaled scores on the WISC-R full scale, verbal scale, or performance scale. For the 22 readers and 23 spellers there was also no relation between age at diagnosis and performance on the reading and spelling tests. Examination of scattergrams of the relations among these variables, however, revealed three cases with an extreme score on only one variable, which may have distorted the relations. These three cases comprised the one whose chronological age was by far the highest at diagnosis (47 months), the one with the lowest chronological age at diagnosis (3 months), and the one with the highest IQ score (full scale $I Q=89$ ). Excluding these three children from the sample, a negative correlation was obtained between age at diagnosis and the sum of scaled scores on the WISC-R performance scale that was just short of conventional significance $(r=-0 \cdot 25$, $p=0 \cdot 06$ ). This suggests a tendency for children who were diagnosed later to perform more poorly on tasks involving non-verbal visuospatial and motor abilities.

Examining the relation between age at diagnosis and the Rutter scales, there were significant positive correlations with the total behavioural deviance scores on the teacher scale $(r=0.30, p=0.027)$ and with the hyperactivity subscale scores on both the teacher and parent scales $(r=0.41, p=0.004$ and $\mathrm{r}=0 \cdot 28, \mathrm{p}=0 \cdot 036$, respectively).

\section{Discussion}

Age at diagnosis has been accepted as the best estimate of duration or severity of hypercalcaemia in this condition. Unlike, for example, congenital hypothyroidism, it is not possible to date the onset of hypercalcaemia. Cases have been documented with normal plasma calcium concentrations at birth and in the first few months of life. ${ }^{21}$ Hypercalcaemia almost certainly develops at variable times during the first year of life. Moreover, plasma calcium concentrations at diagnosis cannot be equated with severity as rapid rises in plasma calcium concentrations might theoretically precipitate earlier diagnosis. This hypothesis is compatible with the present finding that plasma calcium concentrations were inversely related to age at diagnosis $(r=-0 \cdot 26$, $p=0.047$ ), although an alternative explanation for this finding is that it reflects the natural history of hypercalcaemia to resolve over the first few years of life. In either event, recognising its limitations, age at diagnosis seems the best index to study the possible long term effects of idiopathic infantile hypercalcaemia.

In contrast to earlier assumptions, ${ }^{5}{ }^{12}$ we have found no evidence to support the suggestion that earlier diagnosis may alter overall intellectual ability. More detailed analysis of the psychological profile of these children suggests, however, that hypercalcaemia may indeed have long term effects on certain cognitive functions. The peculiar abilities of these children have often been alluded to but untito recently had not been comprehensively studied. We have observed, and reported more extensively? elsewhere, ${ }^{11}$ significantly better verbal scores on the WISC-R than visuospatial and motor skills in these children. Given that later diagnosis of hypercalcaemia is associated with lower scores on the WISC-R performance scale, without a similar effect on verbal scores, it is possible that hypercalcaemia, or a related variable, may have a differential adverse effect on the development of these non-verbal skills.

Behaviour disorders were first noted in this syndrome by Arnold et al, ${ }^{8}$ and their findings have since been confirmed. ${ }^{11}$ The finding that later diagnosis was also associated with more deviant behaviour and hyperactivity later in childhood was unexpected. Effects of ill health and hypercalcaemia can be postulated at several levels - for example, prolonged ill health and feeding problems in infancy would possibly disrupt the development of stable behaviour patterns.

Hypercalcaemia is known to cause psychiatric disturbance in adult life, ${ }^{22}$ and there is now some clinical evidence that it can affect certain areas of psychological development. Detailed histological data on brain morphology from cases with this condition are lacking, and to our knowledge there has been no study of brain cell growth in the presence of hypercalcaemia. Although this study requires confirmation and needs to be extended to 
include cases with the same phenotype but without documented evidence of infantile hypercalcaemia (Williams-Beuren syndrome), there is now some evidence that hypercalcaemia may adversely affect subsequent development and behaviour. Thus although it is fairly rare, it is a condition worthy of note as it is both simple to diagnose and simple to treat.

We thank Sir George and Lady Cynthia Cooper and the members of the Infantile Hypercalcaemia Foundation for generously supporting this research and the children, parents, and teachers who participated in the study.

\section{References}

${ }^{1}$ Fanconi G, Girardet P, Schlesinger B, Butler H, Black JS. Chronische hypercalcaemie kombiniert mit osteosklerose. hyperazotamie, minderwuschs und kongenital missbildungen. Helv Paediatr Acta 1952; 7:314-34.

${ }^{2}$ Lightwood R. Idiopathic hypercalcaemia with failure to thrive. Arch Dis Child 1952;27:302-3.

3 Payne WW. The blood chemistry in idiopathic hypercalcaemia. Arch Dis Child 1952;27:302.

${ }^{4}$ Lightwood R, Stapleton T. Idiopathic hypercalcaemia in infants. Lancet 1953;ii:255-6.

${ }^{5}$ Fraser A, Langford Kidd BS, Kooh SW. Paunier L. A new look at infantile hypercalcaemia. Pediatr Clin North Am 1966; 13:503-25.

6 Joseph MC, Parrott D. Severe infantile hypercalcaemia with special reference to the facies. Arch Dis Child 1958;33:385-95.

${ }^{7}$ Martin NDT, Snodgrass GJAI, Cohen RD. Idiopathic infantile hypercalcaemia-a continuing enigma. Arch Dis Child 1984:59:605-13.

${ }^{8}$ Arnold R, Yule W, Martin NDT. The psychological characteristics of infantile hypercalcaemia: a preliminary investigation. Dev Med Child Neurol 1985;27:49-59.

${ }^{9}$ Bennett FC, La Veck B, Sells CJ. The Williams elfin facies syndrome: the psychological profile as an aid in syndrome identification. Pediatrics 1978;61:303-6.
${ }^{10}$ Kataria S, Goldstein DJ, Kushnick T. Developmental delays in Williams ("elfin facies") syndrome. Appl Res Ment Retard 1984,5:419-23.

"Udwin O, Yule W, Martin N. Cognitive abilities and behavioural characteristics of children with idiopathic infantile hypercalcaemia. J Child Psychol Psychiatry. (In press.)

12 Forfar JO, Tompsett SL. Idiopathic hypercalcaemia of infancy. Adv Clin Chem 1959;2:167-200.

13 Lightwood R. Signification des troubles du metabolisme dans la genese du marasme. Arch Fr Pediatr 1953;10:190-3.

14 Martin NDT, Snodgrass GJAI, Cohen RD, et al. Vitamin D metabolites in idiopathic infantile hypercalcaemia. Arch Dis Child 1985;60:1140-3.

15 Wechsler D. Wechsler intelligence scale for children-revised. Windsor: NFER, 1976.

${ }^{16}$ Neale MD. Neale analysis of reading ability manual. London: Macmillan, 1966.

17 Vernon PE. Graded word spelling test manual. London: Hodder and Stoughton, 1977.

${ }^{18}$ Rutter M. A children's behaviour questionnaire for completion by teachers. Preliminary findings. J Child Psychol Psychiatry 1967;8:1-11.

19 Rutter M, Tizard J, Whitmore K. Education, health and behaviour. London: Longmans, 1970.

${ }^{20}$ Schachar R, Rutter M, Smith A. The characteristics of situationally and pervasively hyperactive children: implications for syndrome definition. $J$ Child Psychol Psychiatry 1981;22:375-92.

21 Jue KL, Noren GR, Anderson RC. The syndrome of idiopathic hypercalcaemia of infancy with associated congenital heart disease. J Pediatr 1965;67:1130-40.

22 Petersen P. Psychiatric disorders in primary hyperparathyroidism. Journal of Clinical Endocrinology 1968;28:1491-5.

Correspondence to Dr O Udwin, Department of Psychology. Institute of Psychiatry, De Crespigny Park, Denmark Hill, London SE5 8AF.

Received 21 July 1986 